\title{
The metabolic syndrome influences the risk of chronic complications in patients with Type II diabetes
}

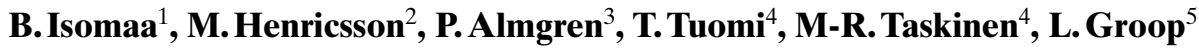 \\ ${ }^{1}$ Jakobstad Hospital, Jakobstad, Finland \\ ${ }^{2}$ Helsingborg Hospital, Helsingborg, Sweden \\ ${ }^{3}$ Wallenberg Laboratory, University of Lund, Malmö, Sweden \\ ${ }^{4}$ Department of Medicine, Helsinki University Hospital, Helsinki, Finland \\ ${ }^{5}$ Department of Endocrinology, University of Lund, Malmö, Sweden
}

\section{Abstract}

Aims/hypothesis. We examined features of the metabolic syndrome to see if they modified the risk of chronic diabetic complications in patients with Type II (non-insulin-dependent) diabetes mellitus.

Methods. A total of 85 randomly selected patients with the metabolic syndrome (WHO definition) were compared with 85 Type II diabetic patients matched for age, sex, duration of diabetes, glycaemic control and without the syndrome to assess the microvascular and macrovascular complications.

Results. The patients with the metabolic syndrome had a higher prevalence of cardiovascular disease (52 vs $21 \%, p<0.001$ ), microalbuminuria or macroalbuminuria (23 vs $7 \%, p=0.003$ ) and distal neuropathy (16 vs $6 \%, p=0.048)$ than patients without the syndrome. The patients with the metabolic syndrome had smaller LDL particle size $(25.4 \pm 1.4$ vs $26.4 \pm 1.1$ $\mathrm{nm} ; p<0.001)$, which correlated with the ratio of se- rum triglycerides to HDL cholesterol $(r=-0.64$, $p<0.001)$. In a multiple logistic regression analysis the metabolic syndrome was associated with coronary heart disease (RR 3.84, $p<0.001)$ and microalbuminuria (RR 3.99, $p=0.01$ ). Small LDL particle size was independently associated with neuropathy ( $\mathrm{RR} 0.58 ; p=0.04)$, whereas a high $\mathrm{HbA}_{1 \mathrm{c}}$ was related to neuropathy (RR $1.69, p=0.04$ ), retinopathy (RR 1.53, $p=0.002$ ) and microalbuminuria (RR $1.54, p=0.01)$.

Conclusion/interpretation. Although chronic hyperglycaemia is the main predictor of microvascular complications in patients with Type II diabetes, this risk is modified by some of the components of the metabolic syndrome. [Diabetologia (2001) 44: 11481154]

Keywords Metabolic syndrome, Type II diabetes, insulin resistance, complications, retinopathy, neuropathy, microalbuminuria, cardiovascular disease.
Type II (non-insulin-dependent) diabetes mellitus is a heterogeneous disease involving both impaired beta-cell function and insulin resistance [1]. A majority of patients with Type II diabetes have features of

\footnotetext{
Received: 9 February 2001 and in revised form: 17 May 2001

Corresponding author: Bo Isomaa, PB 23, Jakobstad Hospital, 68601 Jakobstad, Finland, E-mail: bo.isomaa@fimnet.fi Abbreviations: AER, albumin excretion rate; CHD, coronary heart disease; $\mathrm{CV}$, coefficient of variation; $\mathrm{DR}$, diabetic retinopathy; MSDR + patients, patients with the metabolic syndrome; MSDR-patients, patients without the metabolic syndrome; NPDR, non-proliferative diabetic retinopathy; PDR, proliferative diabetic retinopathy; RR relative risk; WHR, waist-hip ratio
}

the metabolic syndrome, also called "Syndrome X" or the insulin-resistance syndrome [2-3]. The term "Syndrome X" was introduced in 1988 by Reaven who suggested that insulin resistance and compensatory hyperinsulinaemia underlie the clustering of cardiovascular risk factors such as glucose intolerance, hypertension and dyslipidaemia. Several other components have subsequently been added, including obesity and especially abdominal obesity, microalbuminuria, abnormalities in fibrinolysis and coagulation and the presence of small dense atherogenic LDL particles [4-7]. Reports on the prevalence of the metabolic syndrome have varied considerably between studies because the criteria for the definition for the syndrome are not clear [8]. The World Health Orga- 
nisation (WHO) therefore proposed in 1998 a definition for the metabolic syndrome [9]. Although hyperglycaemia is a well established risk factor for microangiopathy in patients with Type II diabetes, it is not known whether this risk is modified by the metabolic syndrome. Some investigators have questioned the connection between the metabolic syndrome and microalbuminuria [10-11]. We aimed to study the impact of different features of the metabolic syndrome on chronic diabetic complications in patients with Type II diabetes.

\section{Subjects and methods}

The diabetic patients were recruited from the Botnia Study in western Finland, in which patients with Type II diabetes and their family members have been enrolled since 1990 [12]. We studied a random sample of 85 patients who fulfilled the criteria for the metabolic syndrome $(\mathrm{MSDR}+)$ and compared them to 85 patients, matched for age, sex and duration of diabetes, who did not fulfil the criteria of the syndrome (MSDR-). Patients with maturity-onset diabetes of the young (MODY) and patients with antibodies to glutamic acid decarboxylase (GADA) were excluded $[13,14]$. The following definitions were used to define the metabolic syndrome and diabetic complications.

Definition of the metabolic syndrome. We used the WHO definition of the metabolic syndrome [9] but the cut-off limits for WHR were adjusted to the distribution of obesity in a Scandinavian population [8]. According to the modified definition, a patient with Type II diabetes has a metabolic syndrome if he or she fulfils at least two of the following criteria: hypertension defined as antihypertensive treatment and or elevated blood pressure $(>160 \mathrm{mmHg}$ systolic or $>90 \mathrm{mmHg}$ diastolic); dyslipidaemia defined as elevated plasma triglyceride $(\geq 1.7 \mathrm{mmol} / \mathrm{l})$ and/or low HDL cholesterol $(<0.9 \mathrm{mmol} / \mathrm{l}$ in men, $<1.0 \mathrm{mmol} / 1$ in women) concentrations; obesity defined as a high BMI $\left(\geq 30 \mathrm{~kg} / \mathrm{m}^{2}\right)$ and or a high waist-to-hip ratio (WHR $>1.0$ in men, $>0.9$ in women) and microalbuminuria (urinary albumin excretion rate $\geq 20 \mu \mathrm{g} / \mathrm{min}$ ).

Neuropathy. Diagnosis of distal sensory neuropathy was based on a clinical examination and a symptom score [15]. The clinical examination included a test of Achilles tendon reflexes, vibration sensation at hallux and sensory perception by a $10 \mathrm{~g}$ Semmes-Weinstein monofilament at three sites on each foot [16]. The maximum score was 10 for the clinical examination and 9 for the symptom questionnaire. The minimum criteria for the diagnosis of sensory neuropathy were moderate signs (score $\geq 6$ ) with or without symptoms or mild signs (score $3-5)$ with moderate symptoms (score $\geq 5$ ).

Neuropathy was also assessed by measuring the vibration perception threshold at ankle with a Vibrameter (Somatomedic productions AB, Sollentuna, Sweden) in 138 patients. In 45 control subjects between 35 and 70 years of age with normal glucose tolerance and no clinical signs of neuropathy, the vibration threshold correlated with height and a height-adjusted threshold exceeding $3.3 \mu \mathrm{m}$ (corresponding to the 95th centile) was considered pathological. In the Type II diabetic patients the height-adjusted vibration threshold correlated with the score from the neurological examination $(r=0.486, p<0.001$, $n=138)$ but not with the score for symptoms $(r=-0.009$, $p=0.92, n=138)$.
Microalbuminuria. Microalbuminuria was considered present if the albumin excretion rate (AER) in overnight urine exceeded $20 \mu \mathrm{g} / \mathrm{min}$ and macroalbuminuria if AER exceeded $200 \mu \mathrm{g} /$ min [17]. For 11 patients an albumin-creatinine ratio (ACR) in the morning urine was used and values exceeding $2.5 \mathrm{mg} /$ $\mathrm{mmol}$ in males and $3.5 \mathrm{mg} / \mathrm{mmol}$ in females were considered as pathological [17]. Two patients with chronic glomerulonephritis of non-diabetic origin were excluded from the analysis of nephropathy.

Retinopathy. Diagnosis of retinopathy was based on fundus photography. Colour fundus photographs were obtained after pharmacological mydriasis at an angle of $45-60^{\circ}$ with a Topcon TRC NW5 fundus camera (Topcon Optical, Tokyo, Japan) or a Canon CF-60U fundus camera (Canon, Tokyo, Japan). The alternative classification of the Wisconsin Epidemiological Study of Diabetic Retinopathy was used to define the retinopathy level [18]. Based on an 11-step scale the retinopathy levels of the patients were divided into four groups; no diabetic retinopathy (DR), mild DR, moderate DR and severe NPDR or PDR [16].

Macular oedema was defined as presence of hard exudates and retinal thickening or both within one disc diameter of the centre of the macula in at least one eye.

In three patients, the diagnosis of retinopathy was based on ophthalmologic hospital records and in one patient on ophthalmoscopy.

Cardiovascular disease. The patient's history of myocardial infarction or strokes was based on information from hospital records. A diagnosis of coronary heart disease was also based upon hospital records or use of nitro-glycerine and pathological findings in resting ECG. The ECGs were coded using the Minnesota codes 1.1-3, 4.1-4, 5.1-3 [19].

Peripheral vascular disease. The diagnosis of peripheral vascular disease was based on palpation of foot pulses, clinical symptoms of claudication and measurement of an ankle-brachial in$\operatorname{dex}(\mathrm{ABI})$ [16]. An ABI-index of less than 0.9 was the criteria used for the diagnosis of peripheral vascular disease [20]. For the multiple logistic regression analysis peripheral vascular disease was defined as a low ABI-index $(<0.9)$ and/or a history of surgical procedures or dilatation of peripheral vessels and/ or symptoms of claudication together with non-palpable foot pulses.

Measurements and assays. Patients were considered to have hypertension if they used antihypertensive drugs or had a mean blood pressure over 160/90 mm Hg during two blood pressure recordings from the right arm at 5 min intervals sitting after $30 \mathrm{~min}$ of at rest. BMI and WHR were measured [16] and GAD antibodies were determined by a modified radiobinding assay using ${ }^{35} \mathrm{~S}$-labelled recombinant human GAD65 [14]. Fasting serum C-peptide concentrations were measured by a radioimmunoassay (Linco Research, St.Charles, Mich., USA) with an interassay CV of $9 \%$. $\mathrm{HbA}_{1 \mathrm{c}}$ concentrations were measured by high-pressure liquid chromatography (Diamat, Hercules, Calif., USA). The reference values for the assay were $4-6 \%$. For the multiple logistic regression analysis we used the mean of $\mathrm{HbA}_{1 \mathrm{c}}$ measurements from the last 5 years (median 4 measurements, range 1-18).

Serum total cholesterol, HDL cholesterol (after precipitation) and triglyceride concentrations were measured on a Cobas Mira analyser (Hoffman LaRoche, Basel, Switzerland). The LDL cholesterol concentrations were calculated using the Friedewald formula [21]. Apolipoprotein A-I and A-II were determined with immunoturbidimetric methods using 
commercially available kits (Boehringer Mannheim, Mannheim, Germany) while apolipoprotein B concentration was measured by an immunochemical assay (Orion Diagnostica, Espoo, Finland). The interassay CV for apolipoprotein A-I, A-II and B were 3.6, 2.1 and $4.9 \%$, respectively. The LDL particle size was determined (59 MSDR + and 70 MSDR- patients) by electrophoresis on gradient polyacrylamide gel [22]. The particle size of two isolated LDL samples were used as a reference and their size was measured by electron microscopy. The calculated mean diameters of LDL standards were 27.9 and $23.9 \mathrm{~nm}$. The mean particle diameter of the major LDL peak was determined by comparing the mobility of the sample to the mobility of the calibrated LDL preparation run on each gel. The intergel CV of the control sample was $1.4 \%$. Urinary albumin concentration was measured by radioimmunoassay (Pharmacia \& Upjohn, Uppsala, Sweden) with a detection limit of $2 \mathrm{mg} / \mathrm{l}$ and an interassay $\mathrm{CV}$ of $5 \%$.

Statistics. The values are presented as Means \pm SD or as a percentage. The significance of differences between group means was tested using the $t$ test after logarithmic transformation of variables not showing normal distribution (triglycerides, HDL cholesterol, ApoA2, ApoB and C-peptide) and after adjustment for BMI. Differences between group frequencies were tested with chi-square $\left(\chi^{2}\right)$ or Fisher's exact test. Correlations were tested using the Spearman rank correlation coefficients. The relation between dependent and independent variables were tested with multiple logistic regression analysis using an SPSS programme for Windows (Chicago, Ill., USA). In all analyses we used mean- $\mathrm{HbA}_{1 \mathrm{c}}$ and duration of diabetes as continuous variables and sex and the metabolic syndrome or the components of the syndrome as categorical variables. We also tested variables related to the different complications in a univariate analysis. A $p$ value of less than 0.05 was considered statistically significant.

\section{Results}

The MSDR + patients had, as expected, higher BMI, WHR, fasting C-peptide, triglyceride (all $p$ values $<0.001)$ and apoB concentrations $(p=0.009)$ as well as lower total HDL $(p<0.001), \mathrm{HDL}_{2}$ $(p=0.008)$ and $\mathrm{HDL}_{3}$ cholesterol $(p<0.001)$ concentrations (Table 1). There was, however, no difference in total cholesterol or LDL cholesterol concentrations between the groups. The LDL particle size was smaller in the MSDR + than in the MSDR-patients $(25.4 \pm 1.4$ vs $26.4 \pm 1.1 \mathrm{~nm} ; p<0.001)$. The triglyceride concentration correlated negatively and the HDL cholesterol concentration positively with the LDL particle size (both $r=0.56 ; p<0.001$ ). Both the ratio of LDL cholesterol to apoB $(r=0.53$, $p<0.001)$ and the ratio of triglycerides to HDL cholesterol $(r=-0.64, p<0.001)$, which have been suggested as surrogate measures for LDL particle size [23], correlated with the LDL particle size. The definition of dyslipidaemia used in the current study (triglycerides $>1.7 \mathrm{mmol} / \mathrm{l}$ and/or HDL cholesterol $<0.9$ in males and $<1.0$ in females) had a sensitivity of $73 \%$ and a specificity of $80 \%$ to detect small, dense LDL particles [24].
Table 1. Clinical characteristics of diabetic patients with and without the metabolic syndrome

\begin{tabular}{|c|c|c|c|}
\hline & MSDR + & MSDR- & $p$-value \\
\hline $\mathrm{N}$ (male/female) & $85(53 / 32)$ & $85(53 / 32)$ & \\
\hline Age (years) & $59.5 \pm 8.8$ & $61.2 \pm 7.5$ & 0.19 \\
\hline Duration (years) & $8.1 \pm 5.8$ & $8.7 \pm 6.4$ & 0.57 \\
\hline \multicolumn{4}{|l|}{ BMI } \\
\hline Male & $30.8 \pm 4.4$ & $26.6 \pm 2.7$ & $<0.001$ \\
\hline Female & $32.3 \pm 5.4$ & $26.7 \pm 3.3$ & $<0.001$ \\
\hline \multicolumn{4}{|l|}{ WHR } \\
\hline Male & $1.02 \pm 0.06$ & $0.97 \pm 0.05$ & $<0.001$ \\
\hline Female & $0.93 \pm 0.05$ & $0.86 \pm 0.05$ & $<0.001$ \\
\hline $\mathrm{HbA}_{1 \mathrm{c}}(\%)$ & $7.9 \pm 1.6$ & $7.5 \pm 1.4$ & 0.06 \\
\hline fS-C-peptide (nmol/l) & $0.77 \pm 0.38$ & $0.55 \pm 0.34$ & $<0.001$ \\
\hline fP-glucose $(\mathrm{mmol} / \mathrm{l})$ & $8.9 \pm 2.8$ & $8.5 \pm 2.8$ & 0.41 \\
\hline Cholesterol $(\mathrm{mmol} / \mathrm{l})^{\mathrm{a}}$ & $5.3 \pm 0.9$ & $5.2 \pm 0.9$ & 0.52 \\
\hline HDL cholesterol $(\mathrm{mmol} / \mathrm{l})^{\mathrm{a}}$ & $1.10 \pm 0.26$ & $1.28 \pm 0.28$ & $<0.001$ \\
\hline $\mathrm{HDL}_{2}$ cholesterol $(\mathrm{mmol} / \mathrm{l})^{\mathrm{a}}$ & $0.30 \pm 0.16$ & $0.40 \pm 0.22$ & 0.008 \\
\hline $\mathrm{HDL}_{3}$ cholesterol $(\mathrm{mmol} / \mathrm{l})^{\mathrm{a}}$ & $0.80 \pm 0.14$ & $0.88 \pm 0.12$ & $<0.001$ \\
\hline LDL cholesterol $(\mathrm{mmol} / \mathrm{l})^{\mathrm{a}}$ & $3.3 \pm 0.9$ & $3.4 \pm 0.8$ & 0.72 \\
\hline Triglycerides $(\mathrm{mmol} / \mathrm{l})^{\mathrm{a}}$ & $1.9 \pm 0.9$ & $1.2 \pm 0.3$ & $<0.001$ \\
\hline ApoA1 $(\mathrm{mg} / \mathrm{dl})^{\mathrm{a}}$ & $128.5 \pm 19.7$ & $134.0 \pm 19.5$ & 0.08 \\
\hline ApoA2 (mg/dl) ${ }^{a}$ & $33.7 \pm 6.4$ & $32.6 \pm 4.8$ & 0.29 \\
\hline ApoB $(\mathrm{mg} / \mathrm{dl})^{\mathrm{a}}$ & $98.2 \pm 18.3$ & $89.1 \pm 20.4$ & 0.009 \\
\hline LDL particle size $(\mathrm{nm})^{\mathrm{a}}$ & $25.6 \pm 1.3$ & $26.4 \pm 1.1$ & 0.001 \\
\hline $\begin{array}{l}\text { Lipid-lowering treatment } \\
(\%)\end{array}$ & 13 & 6 & 0.19 \\
\hline Hypertension (\%) & 81 & 27 & 0.001 \\
\hline Current smoking (\%) & 6 & 8 & 0.77 \\
\hline \multicolumn{4}{|l|}{ Diabetes therapy (\%) } \\
\hline Diet alone & 34 & 35 & 1.00 \\
\hline Oral agents & 27 & 39 & 0.14 \\
\hline Oral agents and insulin & 31 & 13 & 0.009 \\
\hline Insulin & 8 & 13 & 0.45 \\
\hline
\end{tabular}

Values are means $\pm \mathrm{SD}$. Trigycerides, $\mathrm{HDL}, \mathrm{HDL}_{2}$ and $\mathrm{HDL}_{3}$ cholesterol, ApoA2, ApoB and C-peptide were analysed after logarithmic transformation. $T$ test, Fischers exact test were used. HDL cholesterol, trigycerides, apoB, LDL particle size and C-peptide were adjusted for BMI

${ }^{a}$ Patients with lipid-lowering medication excluded

The prevalence of current smokers $(6 \%$ and $8 \%)$ and users of lipid-lowering medication $(13 \%$ and $6 \%$ ) was low in both groups. Antidiabetic treatment regimes differed between the two groups; the combination of insulin and oral agents was more frequent in the group with the metabolic syndrome than in those without it ( $31 \%$ vs $13 \%, p=0.009)$ (Table 1$)$.

Neuropathy. $16 \%$ of the MSDR + patients compared with $6 \%$ of the MSDR-patients had distal neuropathy $(p=0.048)$ (Table 2$)$. There was no difference between the MSDR + and MSDR- patients regarding the height-adjusted vibration threshold $(3.8 \pm 3.0$ vs $3.2 \pm 2.3, p=0.2$ ). Neither did the proportion of patients with a height-adjusted vibrameter value of more than $3.3 \mu \mathrm{m}$ differ between the groups ( $45 \%$ vs $38 \%, p=0.49$ ).

In univariate analysis, neuropathy was related to higher $\mathrm{HbA}_{1 \mathrm{c}}$, longer duration of diabetes, presence of the metabolic syndrome, lower fasting C-peptide concentrations, smaller LDL particle size, insulin 
Table 2. Chronic diabetic complications in patients with and without the metabolic syndrome

\begin{tabular}{lccl}
\hline & MSDR + & MSDR - & $p$-value \\
\hline$N$ (male/female) & $85(53 / 32)$ & $85(53 / 32)$ & \\
Distal neuropathy (\%) & 16 & 6 & 0.048 \\
Elevated vibration threshold (\%) & 45 & 38 & 0.49 \\
AER > 20 $\mu \mathrm{g} / \mathrm{min}(\%)^{\mathrm{a}}$ & 23 & 7 & 0.003 \\
Retinopathy (\%) & 52 & 59 & 0.44 \\
$\quad$ None & 36 & 38 & \\
Mild & 4 & 4 & \\
$\quad$ Moderate & 8 & 0 & 0.01 \\
$\quad$ Severe & 6 & 8 & 0.77 \\
Macular oedema (\%) & 52 & 21 & $<0.001$ \\
Cardiovascular disease (\%) & 52 & 18 & $<0.001$ \\
Coronary heart disease (\%) & 46 & 2 & 0.03 \\
$\quad$ Myocardial infarction (\%) & 12 & 1 & 0.21 \\
Cerebrovascular disease (\%) & 6 & 5 & 0.16 \\
Peripheral vascular disease (\%) & 12 &
\end{tabular}

${ }^{a}$ AER excluded from the definition of the metabolic syndrome

${ }^{\mathrm{b}}$ Cardiovascular disease defined as coronary heart disease and/or cerebrovascular disease and or peripheral vascular disease

treatment and peripheral vascular disease. In a multiple logistic regression analysis (Table 3 ) - which included these variables together with mean $\mathrm{HbA}_{1 \mathrm{c}}$, duration of diabetes, sex and the metabolic syndrome - only $\mathrm{HbA}_{1 \mathrm{c}}(\mathrm{RR} 1.69, p=0.04)$ and LDL-particle size ( $\mathrm{RR} 0.54, p=0.01$ ) were independent risk factors for neuropathy. None of the individual components of the metabolic syndrome was associated with neuropathy (Table 4). Small LDL particle size (cut-off value $25.5 \mathrm{~nm}$ ), adjusted for peripheral vascular disease, was associated with neuropathy (RR 5.4; $p=0.03)$.

Retinopathy. There was no difference in the prevalence of retinopathy between the MSDR + and MSDR-patients ( $48 \%$ vs $41 \%$ ). However, seven of the MSDR + patients $(8 \%)$ had severe retinopathy compared with none of the MSDR- patients $(p=0.01)$. The prevalence of macular oedema did not differ between the groups ( $8 \%$ vs $6 \%$ ).

In univariate analysis, retinopathy was related to longer duration, higher $\mathrm{HbA}_{1 \mathrm{c}}$, lower C-peptide, smaller LDL particle size, hypertension and insulin treatment. In a multiple logistic regression analysis (Table 3) only mean $\mathrm{HbA}_{1 \mathrm{c}}(\mathrm{RR} 1.53, p=0.002)$ and duration of diabetes (RR1.11, $p=0.002)$ were independently related to retinopathy. If the metabolic syndrome was substituted by its components in the regression analysis (Table 4), hypertension (RR 2.24, $p=0.04$ ) was an independent risk factor for retinopathy.

Cardiovascular disease. The prevalence of coronary heart disease was higher in the MSDR + compared to the MSDR- patients $(46 \%$ vs $18 \%$, $p<0.001)$. Altogether $12 \%$ of the MSDR + and $2 \%$ $(p=0.03)$ of the MSDR- patients had a history of myocardial infarction whereas $16 \%$ compared with $7 \%$ $(p=0.09)$ had undergone by-pass surgery or angioplasty. A history of cerebrovascular disease was slightly more common in the MSDR + patients than in the MSDR-patients ( $6 \%$ vs $1 \%$ ).

An ankle-brachial index below 0.9 was seen in $6.1 \%$ of the MSDR + patients and in $2.3 \%$ of the MSDR-patients $(p=0.27)$. If we use the extended definition, peripheral vascular disease was seen in $12 \%$ of the MSDR + and in 5\% of the MSDR- patients $(p=0.16)$.

In univariate analysis, $\mathrm{CHD}$ was related to higher $\mathrm{HbA}_{1 \mathrm{c}}$, smaller LDL particle size, the metabolic syndrome and insulin treatment. No significant relation was seen between CHD and LDL cholesterol or smoking. In a logistic regression analysis (Table 3 ) with coronary heart disease as a dependent variable, the metabolic syndrome was strongly related to coronary heart disease (RR 3.84, $p<0.001$ ). If the metabolic syndrome was substituted by its components in the regression analysis (Table 4), only dyslipidaemia was independently associated with CHD (RR 2.81, $p=0.007)$.

Microalbuminuria. To study whether the metabolic syndrome is associated with microalbuminuria, we excluded microalbuminuria from the criteria of the metabolic syndrome so that a patient was thus considered to have the metabolic syndrome if 2 of the 3 remaining criteria (obesity, dyslipidaemia or hyperten-

Table 3. Risk factors (RR, $95 \%-C I)$ for diabetic complications in patients with Type II diabetes

\begin{tabular}{lllll}
\hline & $\begin{array}{l}\text { Neuropathy } \\
n=126\end{array}$ & $\begin{array}{l}\text { Retinopathy } \\
n=169\end{array}$ & $\begin{array}{l}\text { Microalbuminuria } \\
n=167\end{array}$ & $\begin{array}{l}\text { CHD } \\
n=169\end{array}$ \\
\hline${\text { Mean } \mathrm{HbA}_{1 \mathrm{c}}(\%)}_{\text {Duration (years) }}$ & $1.69(1.00-2.83)^{*}$ & $1.53(1.19-1.99)^{* *}$ & $1.54(1.11-2.15)^{*}$ & $1.18(0.98-1.51)$ \\
Metabolic syndrome & $0.98(0.86-1.11)$ & $1.11(1.04-1.19)^{* *}$ & $1.01(0.93-1.10)$ & $1.01(0.95-1.08)$ \\
Male sex & $0.71(0.14-3.56)$ & $1.23(0.61-2.47)$ & $3.99(1.38-11.5)^{*}$ & $3.84(1.85-7.9)^{* * *}$ \\
LDL particle size $(\mathrm{nm})$ & $2.44(0.42-14.0)$ & $0.80(0.39-1.64)$ & $3.41(1.05-11.1)^{*}$ & $1.87(0.89-3.9)$
\end{tabular}

$* p<0.05, * * p<0.01, * * * p<0.001$

The analysis for neuropathy was also adjusted for peripheral vascular disease. In the analysis of microalbuminuria the defi- nition of the metabolic syndrome was defined as presence of at least two of the three components (obesity, dyslipidaemia and hypertension) 
Table 4. Risk Ratios (RR, $95 \%$-CI) for diabetic complications in patients with Type II diabetes - the metabolic syndrome substituted by its components

\begin{tabular}{lllll}
\hline & $\begin{array}{l}\text { Neuropathy } \\
n=165\end{array}$ & $\begin{array}{l}\text { Retinopathy } \\
n=167\end{array}$ & $\begin{array}{l}\text { Microalbuminuria } \\
n=167\end{array}$ & $\begin{array}{l}\text { Coronary heart disease 7 } \\
n=167\end{array}$ \\
\hline Mean-HbA $1 \mathrm{c}(\%)$ & $1.77(1.19-2.63)^{* * *}$ & $1.56(1.19-2.06)^{* * *}$ & $1.67(1.19-2.36)^{* *}$ & $1.19(0.92-1.54)$ \\
Duration (year) & $1.03(0.94-1.13)$ & $1.10(1.02-1.09)^{*}$ & $0.99(0.91-1.09)$ & $1.03(0.96-1.10)$ \\
Male sex & $2.67(0.72-9.8)$ & $0.98(0.46-2.11)$ & $5.0(1.44-17.4)^{*}$ & $1.72(0.78-3.79)$ \\
Obesity & $1.85(0.57-6.05)$ & $0.71(0.33-1.5)$ & $1.96(0.65-5.89)$ & $1.88(0.89-3.99)$ \\
Dyslipidaemia & $1.44(0.47-4.4)$ & $0.75(0.34-1.66)$ & $1.85(0.67-5.16)$ & $2.81(1.32-5.97)^{* *}$ \\
Hypertension & $2.30(0.70-7.5)$ & $2.24(1.03-4.86)^{*}$ & $5.39(1.67-17.3)^{* *}$ & $1.19(0.55-2.57)$ \\
Microalbuminuria & $0.60(0.14-2.50)$ & $1.66(0.56-4.91)$ & & $1.24(0.45-3.40)$ \\
\hline
\end{tabular}

$* p<0.05,{ }^{* *} p<0.01$

sion) were fulfilled. According to these modified criteria $19.3 \%$ of the MSDR + patients had microalbuminuria and $3.8 \%$ had macroalbuminuria. The corresponding figures for the MSDR- patients were 5.6\% and $1.1 \%$. In univariate analysis, microalbuminuria was related to higher $\mathrm{HbA}_{1 \mathrm{c}}$, smaller LDL particle size, male sex, the metabolic syndrome and insulin treatment. In a logistic regression analysis with microalbuminuria or macroalbuminuria as a dependent variable, the metabolic syndrome (defined without microalbuminuria) ( $\mathrm{RR} 3.99 ; p=0.01$ ), mean $-\mathrm{HbA}_{1 \mathrm{c}}(\mathrm{RR} 1.54, p=0.01)$ and male sex (RR 3.41, $p=0.04$ ) were independent risk factors for albuminuria (Table 3). When the metabolic syndrome was substituted by its components in the logistic regression analysis, hypertension ( $R R$ 5.39, $p=0.005$ ) was independently associated with microalbuminuria (Table 4).

\section{Discussion}

This study underlined the role of chronic hyperglycaemia in predicting neuropathy, retinopathy and microalbuminuria. The metabolic syndrome was strongly associated with cardiovascular disease and microalbuminuria but had little effect on the development of retinopathy and neuropathy. Of note, small dense LDL particles were associated with neuropathy.

In addition to high triglyceride and low HDL cholesterol concentrations, the MSDR + patients also had a smaller LDL particle size than the MSDR-patients. The prevalence of small LDL particle size $(<25.5 \mathrm{~nm})$ was $52 \%$ in the MSDR + compared to $17 \%$ in the MSDR - patients $(p<0.001)$. Small, dense LDL particles are highly atherogenic [25-26] and could explain part of the increased cardiovascular risk associated with high triglycerides and low HDL cholesterol concentrations. A recent study reported a relation between the metabolic syndrome (defined according to the WHO criteria), small LDL particle size pattern and the occurrence of preclinical atherosclerosis (intima-media thickness) in healthy 58-year-old men [27].
Neuropathy. Distal neuropathy was more common in the MSDR + than in the MSDR-patients $(16 \%$ vs $6 \% ; p=0.048)$ suggesting that the metabolic syndrome might influence the development of neuropathy. However, when duration, mean- $\mathrm{HbA}_{1 \mathrm{c}}$ and the metabolic syndrome were included in a multiple logistic regression analysis, only mean $\mathrm{HbA}_{1 \mathrm{c}}$ was an independent risk factor for neuropathy. Of note, peripheral vascular disease was also a strong independent predictor of neuropathy (RR $10.1 ; p=0.004$ ) and low ABI has previously been reported to predict neuropathy [28]. It is, however, not easy to distinguish between symptoms and signs of peripheral vascular disease and neuropathy clinically. Of note, the LDL particle size (but not the metabolic syndrome) was associated with neuropathy and this association was independent of the presence of peripheral vascular disease.

How can the association between small dense LDL particles and neuropathy be reconciled? Oxidative stress and impaired n-6 essential fatty acid metabolism contribute to impaired nerve conduction velocity in diabetic rats and can be corrected by antioxidants such as $\gamma$-linolenic acid and $\alpha$-lipoic acid [29, 30]. Small dense LDL particles are vulnerable to oxidation in the vessel wall [31], but it is not known whether the same applies to peripheral nerves. It is also possible that small dense LDL particles could contribute to impaired microcirculation of the peripheral nerves and thereby cause impaired nerve function.

Retinopathy. The prevalence of any kind of retinopathy $(48 \%$ in the MSDR + and $41 \%$ in the MSDRpatients) is in line with previously reported figures on retinopathy in patients with Type II diabetes [32, 33]. Interestingly, severe retinopathy was seen only in the MSDR + patients. Despite this, the metabolic syndrome did not predict retinopathy or moderate or severe retinopathy in the multiple logistic regression analysis, possibly because of the relatively small number of patients with severe retinopathy. When the metabolic syndrome was replaced by its individual components, hypertension was an independent risk factor for retinopathy (RR 2.24, $p=0.04)$. An associ- 
ation between retinopathy and hypertension has been seen in some studies $[34,35]$. In the prospective Wisconsin study [36], systolic blood pressure predicted progression of retinopathy only in patients under 30 years of age at onset. In the UKPDS tight control of blood pressure reduced the progression rate of retinopathy [37].

Cardiovascular disease. The MSDR + patients reported a higher prevalence of coronary heart disease and previous myocardial infarction compared with the MSDR-patients $(p<0.001)$. There were no differences between the groups with respect to glycaemic control, current smoking or LDL cholesterol concentration. The only significant risk factor for coronary heart disease in the multiple regression analysis was the metabolic syndrome with a risk rate of 3.84 $(p<0.001)$. This increased risk was mainly explained by the presence of dyslipidaemia ( RR 2.8, $p=0.007$ ). The mean $\mathrm{HbA}_{1 \mathrm{c}}$ was only of borderline significance as a risk factor for CHD (RR 1.18; 95\% CI $0.98-1.51)$ in this study. Although there are prospective studies [38-40] suggesting an association between hyperglycaemia and cardiovascular disease, this relation is relatively weak and could be overshadowed by other risk factors. In fact, we have only seen an association between hyperglycaemia and cardiovascular disease in a subgroup of Type II diabetic patients with few features of the metabolic syndrome, i.e. in patients with LADA (latent autoimmune diabetes in adults)[16].

Microalbuminuria. The MSDR + patients had a higher prevalence of microalbuminuria or macroalbuminuria than the MSDR- patients $(23 \%$ vs $7 \%$, $p=0.003)$. In the multiple regression analysis, the metabolic syndrome (RR 3.99, $p=0.01$ ) was the strongest predictor of albuminuria suggesting a close relation between the metabolic syndrome and increased AER. In accordance with previous studies, poor glycaemic control and male sex were also risk factors for microalbuminuria [41, 42]. It should be noted that microalbuminuria is also one of the strongest risk factors for cardiovascular death in patients with Type II diabetes $[8,43]$.

In conclusion, chronic hyperglycaemia is the main predictor of chronic complications in patients with Type II diabetes but risk of chronic complications is modified by the presence of components of the metabolic syndrome. Hypertension increases the risk of retinopathy and albuminuria whereas the presence of small dense LDL particles seems to increase the risk for neuropathy.

Acknowledgements. This study was supported by grants from the Finnish Medical Society (B.Isomaa), the Sigrid Juselius Foundation (L.Groop), the European Economical Community (L.Groop), the Crafoord Foundation (L.Groop), the Swedish Medical Research Council (L.Groop), the Påhlsson Foun- dation (T.Tuomi), the Medical Faculty of Lund University (T.Tuomi) and the Arvid Ohlsson Foundation (M.Henricsson).

The authors are grateful to Topcon Optical Svenska AB for supplying us with a Topcon NW5 camera, to Jakobstad Hospital for the use of a Canon CF-60U camera for fundus photography and to the Botnia research group for technical assistance and support.

\section{References}

1. Beck-Nielsen H, Groop LC (1994) Metabolic and genetic characterization of prediabetic states. Sequence of events leading to non-insulin-dependent diabetes mellitus. J Clin Invest 94: 1714-1721

2. Reaven G (1988) Role of insulin resistance in human disease. Diabetes 37: 1595-1607

3. DeFronzo RA, Ferrannini E (1991) Insulin resistance. A multifaceted syndrome responsible for NIDDM, obesity, hypertension, dyslipidemia and atherosclerotic cardiovascular disease. Diabetes Care 14: 173-194

4. Björntorp P (1994) Abdominal obesity and the metabolic syndrome. Ann Med 24: 465-468

5. Groop L, Ekstrand A, Forsblom C et al. (1993) Insulin resistance, hypertension and microalbuminuria in patients with Type II (non-insulin-dependent) diabetes mellitus. Diabetologia 36: 642-647

6. Yudkin JS (1999) Abnormalities in coagulation and fibrinolysis in insulin resistance. Evidence for a common antecedent? Diabetes Care 22 [Suppl 3]: C 25-C30

7. Reaven GM, Chen Y-DI, Jeppesen J, Maheux P, Krauss RM (1993) Insulin resistance and hyperinsulinemia in individuals with small, dense, low density lipoprotein particles. J Clin Invest 92: 141-146

8. Isomaa B, Almgren P, Tuomi Tet al. (2001) Cardiovascular morbidity and mortality associated with the metabolic syndrome. Diabetes Care 24: 683-689

9. Alberti KGMM, Zimmet PZ for the WHO consultation (1998) Definition, diagnosis and classification of diabetes mellitus and its complications. Diabet Med 15: 539-553

10. Balkau B, Charles MA (1999) Comments on the provisional report from the WHO consultation. European Group for the Study of Insulin Resistance. Diabet Med 16: 442-443

11. Nielsen S, Schmitz O, Örskov H, Mogensen C-E (1995) Similar insulin sensitivity in NIDDM patients with normoand microalbuminuria. Diabetes Care 18: 834-842

12. Groop L, Forsblom C, Lehtovirta M et al. (1996) Metabolic consequences of a family history of NIDDM: The Botnia Study. Evidence for sex-specific parental effects. Diabetes 45: $1585-1593$

13. Lehto M, Tuomi T, Mahtani M et al. (1997) Characterization of the MODY3 phenotype, early-onset diabetes caused by an insulin secretion defect. J Clin Invest 99: 582-591

14. Tuomi T, Carlsson Å-L, Li H et al. (1999) Clinical and genetic characteristics of type 2 diabetes with and without GAD antibodies. Diabetes 48: 150-157

15. Young M, Boulton A, Macleod A, Williams D, Sonksen P (1993) A multicentre study of the prevalence of diabetic peripheral neuropathy in the United Kingdom hospital clinic population. Diabetologia 36: 150-154

16. Isomaa B, Almgren P, Henricsson M et al. (1999) Chronic complications in patients with slowly progressing autoimmune type 1 diabetes (LADA). Diabetes Care 22: $1347-1353$ 
17. Mogensen CE, Keane W, Bennett P et al. (1995) Prevention of diabetic renal disease with special reference to microalbuminuria. Lancet 346: 1080-1084

18. Klein R, Klein B, Magli Y, Brothers R, Meuer S, Davies M (1986) An alternative method of grading diabetic retinopathy. Ophthalmology 93: 1183-1187

19. Rose GA, Blackburn H (1968) Cardiovascular survey methods, WHO Monograph Series No.56. World Health Organisation, Geneva

20. Leng GC, Fowkes FGR, Lee AJ, Dubar J, Housley E, Ruckley CV (1996) Use of ankle brachial pressure index to predict cardiovascular events and death: a cohort study. BMJ 313: 1440-1443

21. Friedewald WT, Levy RI, Fredrickson DS (1972) Estimation of the concentration of low density lipoprotein cholesterol in plasma without use of preparative ultracentrifugation. Clin Chem 18: 499-502

22. Lahdenperä S, Sane T, Vuorinen-Markkola H, Knudsen P, Taskinen M-R (1995) LDL particles in moderately hypertriglyceridemic subjects: relation to insulin resistance and diabetes. Atherosclerosis 113: 227-236

23. Boizel R, Benhamou PY, Lardy B, Laporte F, Foulon T, Halimi S (2000) Ratio of triglycerides to HDL cholesterol is an indicator of LDL particle size in patients with type 2 diabetes and normal HDL cholesterol levels. Diabetes Care 23: 1679-1685

24. Austin MA, Breslow JL, Hennekens CH, Buring JE, Willett WC, Krauss RM (1988) Low-density lipoprotein subclass patterns and risk of myocardial infarction. JAMA 260: 1917-1921

25. Gray RS, Robbins DC, Wang W et al. (1997) Relation of LDL size to the insulin resistance syndrome and coronary heart disease in american indians. The Strong Heart Study. Arterioscler Thromb Vasc Biol 17: 2713-2720

26. Lamarche B, Tchernof A, Moorjani S et al. (1997) Small, dense low-density lipoprotein particles as a predictor of the risk of ischemic heart disease in men. Prospective results from the Québec Cardiovascular Study. Circulation 95: 69-75

27. Hulthe J, Bokemark L, Wikstrand J, Fagerberg B (2000) The metabolic syndrome, LDL particle size, and atherosclerosis. Arterioscler Thromb Vasc Biol 20: 2140-2147

28. Adler IA, Boyko EJ, Ahroni JH, Stensel V, Forsberg RC, Smith DG (1997) Risk factors for diabetic peripheral sensory neuropathy. Results from the Seattle Prospective Diabetic Foot Study. Diabetes Care 20: 1162-1167

29. Van Dam PS, Van Asbeck BS, Erkeleus DW, Marx JJM, Gispen W-H, Bravenboer B (1995) The role of oxidative stress in neuropathy and other diabetic complications. Diabetes Metab Rev 11: 181-192

30. Cameron NE, Cotter MA, Horrobin DH, Tritschler HJ (1998) Effects of $\alpha$-lipoic acid on neurovascular function in diabetic rats: interaction with essential fatty acids. Diabetologia 41: 390-399

31. Steinberg D, Lewis A (1997) (Connor Memorial Lecture) Oxidative modification of LDL and atherogenesis. Circulation 95: 1062-1071

32. Klein R, Klein BEK, Moss SE, Davies MD, DeMets DL (1984) The Wisconsin Epidemiologic Study of Diabetic Retinopathy III. Prevalence and risk of diabetic retinopathy when age at diagnosis is 30 or more years. Arch Ophthalmol 102: 527-532

33. Henricsson M, Nilsson A, Groop L, Heijl A (1996) Prevalence of diabetic retinopathy in relation to age at onset of the diabetes, treatment, duration and glycemic control. Acta Ophthalmol Scand 74: 523-527

34. Teuscher A, Schnell H, Wilson PWF (1988) Incidence of diabetic retinopathy and relationship to baseline plasma glucose and blood pressure. Diabetes Care 11: 246-251

35. Hamman RF, Mayer EJ, Moo-Young GA, Hildebrandt W, Marshall JA, Baxter J (1989) Prevalence and risk factors of diabetic retinopathy in non-Hispanic whites and Hispanics with NIDDM. San Luis Valley Diabetes Study. Diabetes 38: $1231-1237$

36. Klein BEK, Klein R, Moss SE, Palta M (1995) A cohort study of the relationship of diabetic retinopathy to blood pressure. Arch Ophthalmol 113: 601-606

37. UK Prospective Diabetes Study Group (1998) Tight blood pressure control and risk of macrovascular and microvascular complications in type 2 diabetes: UKPDS 38. BMJ 317: 703-713

38. Laakso M (1999) Hyperglycemia and cardiovascular disease in type 2 diabetes. Diabetes 48: 937-942

39. Haffner SM (1999) Epidemiological studies on the effect of hyperglycemia and improvement of glycemic control on macrovascular events in type 2 diabetes. Diabetes Care 22 [Suppl 3]: C54-C56

40. Turner RC, Millns H, Neil HAW et al. for the United Kingdom Prospective Diabetes Study Group (1998) Risk factors for coronary artery disease in non-insulin-dependent diabetes mellitus: United Kingdom prospective diabetes Study (UKPDR: 23). BMJ 316: 823-828

41. Gall M-A, Hougaard P, Borch-Johnsen, Parving H-H (1997) Risk factors for development of incident and overt diabetic nephropathy in patients with non-insulin dependent diabetes mellitus: prospective, observational study. BMJ 314: 783-788

42. Forsblom C, Groop P-H, Tötterman KJ, Sane T, Saloranta C, Groop L (1998) Predictors of progression from normoalbuminuria to microalbuminuria in NIDDM. Diabetes Care 21: $1932-1938$

43. Dinneen SF, Gerstein HC (1997) The association of microalbuminuria and mortality in non-insulin-dependent diabetes mellitus. A systematic overview of the literature. Arch Intern Med 157: 1413-1418 